\title{
El agregado de dexametasona no mejoró el tratamiento de la meningitis en niños
}

Dexamethasone treatment in childhood bacterial meningitis in Malawi: a randomised controlled trial. Molyneux $\mathrm{E}$, Walsh $\mathrm{A}$, Forsyth $\mathrm{H}$ y col. Lancet 2002; 360:211-18.

\section{Objetivo}

Evaluar si el agregado de dexametasona $(0,4 \mathrm{mg} / \mathrm{kg}$ día cada 12 horas durante las primeras 48 horas) previo al tratamiento antibiótico habitual disminuía la mortalidad y las secuelas en niños con meningitis bacteriana.

\section{Diseño}

Ensayo clínico aleatorizado doble ciego con un seguimiento de seis meses.

\section{Lugar}

Se realizó en el Queen Elizabeth Central Hospital en Blantyre, Malawi (África).

\section{Pacientes}

Se incluyeron 598 niños entre 2 meses y 13 años (edad promedio: 14 meses) que se presentaron al hospital entre Julio 1997 y Marzo 2001 con sospecha clínica de meningitis mas recuento de glóbulos blancos en la punción lumbar $\geq 100 / \mathrm{ml}$ o tinción de Gram positiva o cultivo positivo.Se excluyeron aquellos niños que hubieran recibido antibióticos de amplio espectro en las 24 horas previas.

\section{Intervención}

Se aleatorizó a los pacientes a la adición de dexametasona $(n=305)$ o placebo $(n=293)$ al tratamiento antibiótico habitual de penicilina $200.000 \mathrm{Ul} / \mathrm{kg}$ cada 24 horas mas cloranfenicol $100 \mathrm{mg} / \mathrm{kg}$ día cada 6 horas. Si la respuesta no era favorable se repetía la punción lumbar y se cambiaba el antibiótico por ceftriaxona $50 \mathrm{mg} / \mathrm{kg}$ cada 12 horas durante 7 días (hecho que sucedió por igual en ambos grupos).

\section{Medición resultados principales}

El resultado principal fue muerte y los resultados secundarios fueron secuelas (neurológica y auditiva).

Los pacientes fueron evaluados al alta, al mes y a los 6 meses por 2 enfermeras entrenadas.Se realizaron tests neurológicos, de desarrollo (mediante examen físico), evaluaciones auditivas (audiometrías) y visuales.

\begin{tabular}{l|r|r|c}
$\begin{array}{l}\text { CONDICIÓN } \\
\text { (a los } 6 \text { meses de seguimiento) }\end{array}$ & $\begin{array}{c}\text { Grupo Intervención } \\
(\mathbf{n}=305)\end{array}$ & $\begin{array}{c}\text { Grupo Placebo } \\
(\mathbf{n}=\mathbf{2 9 3})\end{array}$ & $\mathbf{P}$ \\
\hline Muerte & $99(32 \%)$ & $93(32 \%)$ & NS \\
\hline Secuelas en los sobrevivientes & $206(68 \%)$ & $200(68 \%)$ & NS \\
\hline Con déficit neurológico $n$ & $69(33 \%)$ & $56(28 \%)$ & NS \\
\hline Con secuelas auditivas a & $86(42 \%)$ & $77(38 \%)$ & NS \\
\hline No evaluados & $34(16 \%)$ & $31(15 \%)$ & NS \\
\hline
\end{tabular}

\section{${ }^{*}$ NS:No significativo}

$\mathrm{n}$ : Parálisis cerebral y retraso madurativo fueron las dos secuelas más comunes.

a:Sordera bilateral fue la secuela más común seguida de sordera unilateral.

\section{Conclusiones}

El agregado de dexametasona al tratamiento antibiótico habitual en niños con meningitis no mostró ningún beneficio en relación a la tasa de mortalidad o a las secuelas tanto auditivas como neurológicas, en un país de bajos recursos.

Fuente de financiamiento:División de Salud y Desarrollo de la Infancia y Adolescencia (Organización Mundial de la Salud)

\section{Comentario}

La meningitis bacteriana es un problema de salud diez veces más frecuente en países en desarrollo que en países desarrollados. En países con bajos recursos la mortalidad es del $15-50 \%$ mientras que en los países desarrollados es del $5 \%$.De los sobrevivientes, alrededor del $15-20 \%$ presentan algún grado de secuela neurológica en los países desarrollados ${ }^{1}$. En nuestro país en un trabajo realizado en el Hospital de Niños "Dr. R. Gutiérrez" la mortalidad y la tasa de secuelas fueron del $15 \%$ y $21 \%$ respectivamente ${ }^{2}$.

El agregado de corticoides a la terapia antibiótica no se recomendó hasta 1994 debido a falta de información sobre su beneficio, actualmente se propone su uso para disminuir las secuelas auditivas predominantemente y en las meningitis causadas por Haemophilus influenzae tipo B. ${ }^{2 \cdot 3}$

Se supone cierta diferencia entre los países desarrollados y los de bajos recursos en relación a la mortalidad y tasa de complicaciones. Esto se atribuye a diferencias en la prevalencia de infecciones por Haemophilus (menor en los países desarrollados debido a mayor tiempo de vacunación ob ligatoria) y a características distintas de los sistemas de salud (menores recursos y retrasos en la búsqueda de atención en los países en desarrollo).

En este ensayo clínico los investigadores aportan información en relación al uso de corticoides en los países en desarrollo, no encontrando ningún beneficio de los mismos. Tampoco encuentran diferencias en las complicaciones o mortalidad analizando en forma separada las distintas etiologías, aunque este hallazgo puede deberse a que en el análisis de subgrupos el poder del estudio no fue lo suficientemente elevado para detectarla ni fue el objetivo primario del estudio. Otros trabajos realizados en países en desarrollo coinciden con este hallazgo de no diferencia, ${ }^{4}$ planteándose el interrogante en relación a si existe una acción diferencial de la dexametasona dependiendo de la situación del país en cuestión. Es interesante, al evaluar la efectividad de un tratamiento, tener en cuenta otros determinantes del pronóstico de la enfermedad, como son en este caso la desnutrición, anemia, retraso en la demanda y menor cobertura de vacunación que presentan gran diferencia entre distintos países acorde a las distintas situaciones locales.

Conclusiones del comentario: Es consistente la evidencia de ineficacia de los corticoides en el tratamiento de la meningitis en países en desarrollo.La generación de información clínica teniendo en cuenta las diferencias regionales hace más fácil la toma de decisiones en distintos contextos de atención.

\section{Dr. Sebastián García Martí [ Becario Gerenciamiento Plan de Salud.Hospital Italiano Buenos Aires ]}

\section{Referencias}

1.WHO.Antimicrobial Therapy for bacterial meningitis.Meeting report from WHO June 18-20, 1997

2. Libro Azul de Infectología Pediátrica. Segunda Edición.Comité Nacional de Infectología Pediátrica, 2000.

3 McIntyre PB, Berkey CS, King SM, et al. Dexamethasone as adjunctive therapy in bacterial meningitis:a meta-analysis of randomized clinical trials since 1988.JAMA. 1997 Sep 17;278:925-31.

4 Qazi SA, Khan MA, Mughal N, et al. Dexamethasone and bacterial meningitis in Pakistan. Arch Dis Child. 1996;75:482-488. 